\title{
correspondence
}

\section{Neuberger on nutrition}

SIR,--I have considered myself a nutritionist for nearly 40 years, and I doubt whether even in the 1930 s I would have ignored the teachings of John Boyd Orr and Frederick Gowland Hopkins in order to accept the description of nutrition that forms the first sentence of the Neuberger report: "The science of human nutrition is mainly concerned with defining the optimum amounts of the constituents of food necessary to achieve or maintain health."

Nutrition, on the contrary, is to do with the whole relationship between man and what he eats, that is, it is to do with food: how food is produced; what determines which foods we eat and how much; what the constituents of food are; which of these the body requires and in what amounts; how these constituents are dealt with in the body and what functions they perform; what happens when the required amounts of the required constituents are not provided or are exceeded; what steps can be taken to avoid these differences between what is needed and what is consumed. Nutrition, therefore, has reference to economics, anthropology, sociology, demography and psychology, as well as to chemistry, biology, biochemistry and physiology. In particular, nutrition is the one science that can least afford to remain in the laboratory; it concerns every single human being, every single day of his life.

What enthusiasm the report shows is confined largely to its summary of existing knowledge of the biochemical aspects of nutrition, and much of its recommendations for further research are also in this area. There is only an occasional brief reference to nutrition as it affects the whole body and an even less frequent nod towards the need to know more about people's nutritional behaviour. This bias is really not good enough; the human body exists together with other human bodies in a social and cultural environment, and important as biochemistry is, it is as important-and possibly more soto know what determines the diets of different people, in different groups, at different times. Certainly we need to know more about energy transformation in the body and the mechanisms that control body weight and body composition. But of more immediate relevance to problems of malnutrition is the scarch for answers to quite dif- ferent questions: Why do some people find it easy to cure their obesity and others find it difficult? Why are so many of the obese so easily persuaded that they can solve their problem by eating Ryvita or yoghurt, or by swallowing slimming pills that contain nothing but aperients, or by going to expensive but quite ineffective slimming clinics?

In this country, and in other countries in the western world, there is a considerable and increasing demand for so-called health foods. What is it that makes so many people entirely ignore the knowledge so laboriously acquired by nutritional research in favour of the incorrect or misleading information that makes them buy brown sugar, brown bread, sea salt, honey and vitamin pills to ensure that they are adequately nourished, or that makes them believe that there is special virtue in brown eggs or in vegetables grown with compost rather than with chemical fertilisers? And why do we continue to act as if it is still true that adequate nutrition in the industrialised countries is largely a matter of economic circumstance-as if all that matters is that a family shall have an adequate income -when it has been demonstrated in the USA, for example, that there has been an increase in the proportion of families eating a poor diet at the same time as family incomes have increased? Again it is just not good enough for the nutritionist to ignore these views, held as they often are by sincere and highly intelligent people, however misguided. Even less is it good enough for us to smile a superior smile and tell such people-and tell each other with a wink-how stupid these views are.

It is because nutritionists know that such matters are important that research carried out in departments of nutrition today is concerned not only with the physiological and biochemical problems that the report concentrates on so heavily, but with broader subjects too: the factors that determine food choice, the influence of diet on behaviour and of behaviour on diet, the assessment of attitudes towards foods and nutrition, and the differences between what pcople think about food and what in fact they eat. In the university department that I know--that at Queen Elizabeth College, Londonmore than 300 research papers were published between the start of the degree course in nutrition in 1953 and my retirement from the Chair of
Nutrition in 1971.

The report deplores the "relative neglect of human nutrition" as a subject for research. I suggest that this neglect is, more than anything else, a consequence of the existence of a myth about what nutrition is. The myth is that nutritional science is mostly to do with "defining the optimum amounts of the constituents of food". It is the narrowness of this account of nutrition that has been largely responsible for the subject's failure to attract either the research support or the attention of young scientists to the extent that its interest and importance deserve. Although the report deplores these consequences, it perpetuates the myth that has helped to create them. Yours faithfully, JOHN YUDKIN

London NW3, UK

\section{Asbestosis}

SIR,---The best comment to be made on P. F. Holt's letter (January 10) about complacency over asbestosis is contained in the latest Annual Report of HM Chief Inspector of Factories, which says in relation to new cases of asbestosis and mesothelioma, and the latest figures, that they "reflect conditions in the past when, in the then state of knowledge, it could not be ascertained with any certainty what levels of air contamination by asbestos dust would endanger health". Later, describing a major long term medical environmental survey of asbestos workers, he says: "In Phase II of the survey, which embraced the larger manufacturers of asbestos products, 5,000 workers were medically examined and 700 representative personal samples were taken in the workers' breathing zones over 4-hour working periods. The results, which were most encouraging, showed that $92.6 \%$ of the dust counts taken were below the very stringent hygiene standard of two fibres/ml and reflect the very great efforts made by the major firms in the industry to improve standards of control."

$\mathrm{Mr}$ Holt's references to a London life of insulation from reality are wide of the mark. I work in Manchester, the geographical centre of the British asbestos industry, and spend much of my time in asbestos factories. Yours faithfully, W. P. HOWARD

The Asbestos Information Committee, Manchester, $U K$ 